\title{
Change of antioxidant compounds of spices during drying
}

\author{
Andrea Kántor - Loránd Alexa - Emőke Papp-Topa - Béla Kovács - Nikolett Czipa \\ University of Debrecen, Faculty of Agricultural and Food Sciences and Environmental Management, Institute of Food Science, Debrecen \\ kantor.andrea@agr.unideb.hu
}

\begin{abstract}
SUMMARY
Spices and herbs have been used by humanity for thousands of years, so they are very important plants.

In this study, the change of dry matter content and antioxidant compounds of eight spices (basil, thyme, rosemary, mint, parsley, lemongrass, chives, coriander) have been examined the raw plants and in plants preserved by three different drying methods (an oven in 50-60 ${ }^{\circ}$; drying at room temperature; lyophilisation between -40 and $-50^{\circ} \mathrm{C}$, under pressure), because we wanted to see the change of the parameters.

The water content of raw plants was very high, i.e. the dry matter content was very low. By the application of the three drying methods nearly $100 \%$ of the water has left the plants, with the exception of the lyophilized basil and rosemary.

Based on the results related to the original material, lyophilized has proved to be the best treatment for the preservation of antioxidant compounds, however air drying also showed high results for some spices.
\end{abstract}

Keywords: spices, dry matter content, total phenolic content, flavonoid content

\section{INTRODUCTION}

Herbs and spices have a great importance in human nutrition, they have been used by the civilization for thousands of years. The first written records can be read in the Ebers Papyrus, which was written in 1550 B.C. Trade of spices is significant, its history goes back almost 3500 years. These plants has been used for pharmaceutical aims, and to provide the proper colour, taste and aroma of different foods, and to preserve food and beverages (Embuscado, 2015). In Hungary, these plants have been collected or cultivated in domestic gardens for hundreds of years. The $1^{\text {st }}$ World War gave a breakthrough, herbs and aromatic plants became the focus of attention because of the shortage of medicine. The $2^{\text {nd }}$ World War also had a positive effect on the spread of herbs and spices, and on the development of the industries. These plants are commonly used in different industries nowadays, such as pharmaceutical, cosmetic and chemical industry (Bernáth, 2000).

These plants are extraordinary sources of antioxidant compounds (Embuscado, 2015). Their antioxidant property is provided by different components, such as polyphenols, flavonoids, saponins, coumarins and carotenoids (Murica et al., 2004). The importance of antioxidant compounds is to reduce the risk of degenerative diseases caused by oxidative stress. Antioxidant compounds of foods could be primary or secondary basis (Shahidi, 2015).

These compounds could be extremely sensitive, this is why it is important to determine the preservation parameters of them precisely. The collection of plants is followed by storage and processing. It is possible to store the raw plants, but the most commonly used preservation method is drying. Besides natural drying, artificial drying procedures also have to be mentioned, which could be divided into three groups: cold $\left(15-25^{\circ} \mathrm{C}\right)$, warm $(30$ $\left.80^{\circ} \mathrm{C}\right)$ and hot $\left(200-1000^{\circ} \mathrm{C}\right)$ air drying (Bernáth and Németh, 2007). Furthermore, freeze drying (lyophilisation) and the use of microwave ovens are also preferred. Sun drying could decrease the quantity of different aroma components, so longer drying in shadow could be more beneficial (Gibson, 2018).

\section{MATERIALS AND METHODS}

In this study, eight spices (Table 1) were drying with different methods and measured the changes of dry matter content and antioxidant compounds. Tests were also performed on raw samples. 5 pieces of each plant have been bought in different hypermarkets. Parts of the plants intended for consumption were homogenized and then three drying methods have been used which were: drying with oven (dried on 50$60^{\circ} \mathrm{C}$ ), drying on room temperature (air dried) and freeze drying (lyophilized, between -45 and $-50^{\circ} \mathrm{C}$, under pressure). The measurements were carried out in triplicate.

Table 1

Examined samples name

\begin{tabular}{ll}
\hline 1 & basil \\
2 & thyme \\
3 & rosemary \\
4 & mint \\
5 & parsley \\
6 & lemongrass \\
7 & chives \\
8 & coriander \\
\hline
\end{tabular}

\section{Determination of dry matter content}

Petri dishes were dried in an oven, then cooled down in a desiccator and their weight were measured. The homogenized samples were measured into the dishes. Then the dishes containing the samples had been put into the oven and dried to constant weight, then cooled in the desiccator. After cooling, the common weight of the dish and the sample was 
measured, then dry matter content had been calculated by using the original and the dried weight of the dishes and the samples. The results were presented in percentage (Czipa, 2014).

\section{Determination of total polyphenol content}

Total Polyphenol Content (TPC) was determined according to the Folin-Ciocalteu method (Singleton et al., 1999). In this methods include the samples soaked in a mixture of methanol:distilled water (80:20). After the filtration, different reagents were added. In case of TPC, for the calibration gallic acid was used. The mixtures had to stand in the dark for two hours, then their absorbance was measured on $760 \mathrm{~nm}$. The obtained results are reported in $\mathrm{mgGAE} / 100 \mathrm{~g}$.

\section{Determination of flavonoid content}

Flavonoid content was measured by the method of Kim et al. (2003). In case of flavonoid content, for the calibration, catechin was used. The results are expressed in $\mathrm{mgCE} / 100 \mathrm{~g}$. Like the total polyphenol content methods, plants were soaked in a mixture of methanol:distilled water (80:20), and reagents described by a method were added to the samples after the filtration. The absorbance was measured on 510 nm.

\section{RESULTS AND DISCUSSION}

\section{Results of dry matter content}

Dry matter content (Table 2) of plants has also been measured when raw and after preservation.

Table 2

Dry matter content of plants in percentage (\%)

\begin{tabular}{lcccccccc}
\hline & Basil & Thyme & Rosemary & Mint & Parsley & Lemongrass & Chives & Coriander \\
\hline Raw & $10.1 \pm 0.1$ & $20.8 \pm 0.2$ & $15.5 \pm 0.1$ & $16.9 \pm 0.1$ & $13.5 \pm 0.1$ & $11.7 \pm 0.5$ & $8.04 \pm 0.04$ & $7.02 \pm 0.20$ \\
Dried & $100 \pm 0$ & $100 \pm 0$ & $100 \pm 0$ & $100 \pm 0$ & $100 \pm 0$ & $100 \pm 0$ & $100 \pm 0$ & $100 \pm 0$ \\
Air dried & $93.1 \pm 0.6$ & $92.9 \pm 0.5$ & $96.2 \pm 0.4$ & $95.3 \pm 0.2$ & $96.6 \pm 0.7$ & $99.5 \pm 0.6$ & $99.4 \pm 0.9$ & $99.2 \pm 1.1$ \\
Lyophilized & $61.1 \pm 1.6$ & $96.3 \pm 1.7$ & $62.3 \pm 1.7$ & $94.4 \pm 0.1$ & $93.3 \pm 1.7$ & $95.5 \pm 1.1$ & $98.6 \pm 2.0$ & $94.1 \pm 2.0$ \\
\hline
\end{tabular}

Dry matter content of raw plants was between $7.02 \pm 0.20 \%$ (coriander) and $20.8 \pm 0.2 \%$ (thyme), it can be established that spices possess high water content. The dry matter content of dried samples was $100 \%$. In the case of air dried samples values were measured between $92.9 \pm 0.5 \%$ (thyme) and $99.5 \pm 0.6 \%$ (lemongrass), i.e. they hardly had any water left. With the lyophilized plants the lyophilisation of basil and rosemary showed only partial success, as the shown by the results the dry matter content of plants was only around $60 \%$, as opposed to the other plants.

\section{Results of total polyphenol content}

Figure 1 shows the total polyphenol content of plants related to dry matter.

In each case raw samples have highest values for dry matter. Outstanding values were measured in basil and rosemary, followed by thyme, parsley and mint, whose results were between 400 and $500 \mathrm{mgGAE} / 100$ g. The lowest levels of polyphenol, i.e. 290-350 mgGAE/100 g were measured in lemongrass, chives and coriander.

Basil, thyme, rosemary and mint had values above $200 \mathrm{mgGAE} / 100 \mathrm{~g}$ in the lyophilized sample; $199 \pm 5$ $\mathrm{mgGAE} / 100 \mathrm{~g}$ was measured in parsley. All the other plants showed lower total polyphenol content.

In the case of air dried spices four plants (basil, thyme, mint, lemongrass) had values above 200 mgGAE/100 $\mathrm{g}$ also. Regarding the other four plants values lower than $200 \mathrm{mgGAE} / 100 \mathrm{~g}$ were measured as well.

Drying only increased the total polyphenol content above $200 \mathrm{mgGAE} / 100 \mathrm{~g}$ in case of thyme and parsley. All the other measurement showed lower values.

Figure 1: The spices total polyhenol content for dry matter

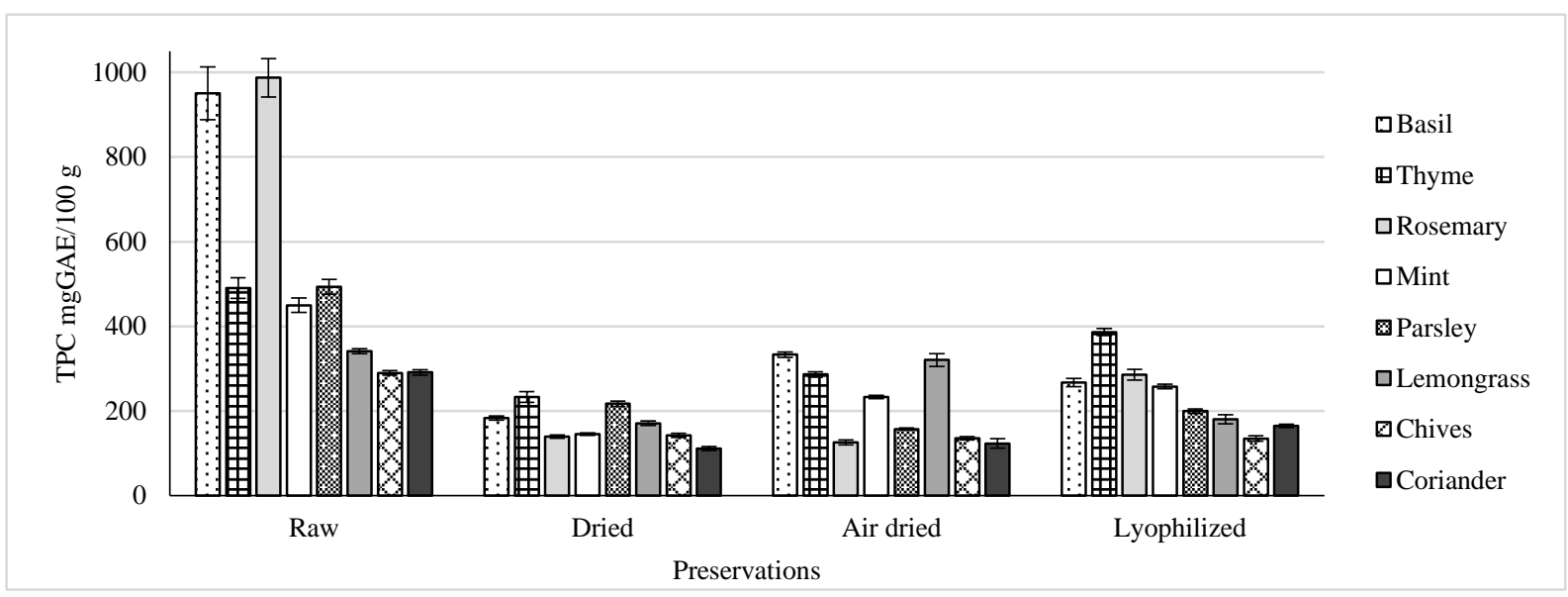


In the case of basil raw samples showed values around $1000 \mathrm{mgGAE} / 100 \mathrm{~g}$. High values (333 \pm 6 mgGAE/100 g) were recorded at air drying. The total polyphenol content of lyophilized basil was $267 \pm 10$ mgGAE/100 g, while with dried plants it was $183 \pm 5$ $\mathrm{mgGAE} / 100 \mathrm{~g}$.

The total polyphenol content of raw thyme $(490 \pm 24 \mathrm{mgGAE} / 100 \mathrm{~g})$ was lower than that of basil or rosemary. Lyophilisation reduced this value $(386 \pm 8$ mgGAE/100 g) to a lesser extent in case of basil and rosemary. Neither air drying nor drying decreased the total polyphenol content below $200 \mathrm{mgGAE} / 100 \mathrm{~g}$.

In the case of rosemary the highest total polyphenol content was measured in the raw samples $(987 \pm 45 \mathrm{mgGAE} / 100 \mathrm{~g})$ for dry matter. Values of the lyophilized samples was $286 \pm 13 \mathrm{mgGAE} / 100 \mathrm{~g}$, while with dried plants $(139 \pm 4 \mathrm{mgCE} / 100 \mathrm{~g})$ and air dried spices $(126 \pm 6 \mathrm{mgCE} / 100 \mathrm{~g})$ showed lower total polyphenol content.

The values were similar in the case of air dried $(233 \pm 4 \mathrm{mgCE} / 100 \mathrm{~g})$ and lyophilized $(257 \pm 5$ $\mathrm{mgCE} / 100 \mathrm{~g}) \mathrm{mint}$. In raw mint $(450 \pm 17 \mathrm{mgGAE} / 100$ g) value was higher nearly twice compared to previous one. The lowest total polyphenol content was measured after drying (145 $\pm 3 \mathrm{mgGAE} / 100 \mathrm{~g}$ ).

Like all plants, in the raw parsley showed the highest total polyphenol content $(493 \pm 18 \mathrm{mgGAE} / 100$ g). After drying and lyophilisation samples has contained similar values $(217 \pm 6$ and $199 \pm 5$ mgGAE/100 g). In case of this plants the air drying decreased to large extent total polyphenol content $(157 \pm 2 \mathrm{mgGAE} / 100 \mathrm{~g})$.

The raw $(341 \pm 6 \mathrm{mgGAE} / 100 \mathrm{~g})$ and air dried (321 \pm 15 mgGAE/100 g) lemongrass values were similar. Another interesting feature is that nearly identical results were obtained by drying (171 \pm 5 mgGAE / $100 \mathrm{~g})$ and lyophilisation $(180 \pm 10 \mathrm{mg}$ $\mathrm{GAE} / 100 \mathrm{~g})$.

In the case of chives similar total polyphenol content were measured after drying (142 \pm 5 mgGAE/100 g), air drying (136 $\pm 4 \mathrm{mgGAE} / 100 \mathrm{~g})$ and lyophilisation $(135 \pm 6 \mathrm{mgGAE} / 100 \mathrm{~g})$. Raw chives values was $290 \pm 5 \mathrm{mgGAE} / 100 \mathrm{~g}$.

In raw coriander (291 \pm 6 mgGAE / 100 g), almost the same total polyphenol content was measured as in raw chives. After lyophilization the sample conatined $165 \pm 4 \mathrm{mgGAE} / 100 \mathrm{~g}$ total polyphenol. With dried $(111 \pm 5 \mathrm{mgGAE} / 100 \mathrm{~g})$ and air dried samples $(123 \pm 11$ mgGAE/100 g) showed similar values.

In case of the total polyphenol contents related to the original matter (Table 3), it can be seen, that raw samples had the lowest concentrations, because these plants had been high water content. Only thyme and rosemary had contained over $100 \mathrm{mgGAE} / 100 \mathrm{~g}$ total polyphenol. The lowest total polyphenols were in coriander.

Plants total polyphenol content for original matter (mgGAE/100 g)

\begin{tabular}{|c|c|c|c|c|c|c|c|c|}
\hline & Basil & Thyme & Rosemary & Mint & Parsley & Lemongrass & Chives & Coriander \\
\hline Raw & $96.0 \pm 6.3$ & $102 \pm 5$ & $153 \pm 7$ & $76.0 \pm 2.9$ & $66.6 \pm 2.4$ & $39.9 \pm 0.7$ & $23.3 \pm 0.4$ & $20.4 \pm 0.4$ \\
\hline Dried & $183 \pm 5$ & $233 \pm 13$ & $139 \pm 4$ & $145 \pm 3$ & $217 \pm 6$ & $171 \pm 5$ & $142 \pm 5$ & $111 \pm 5$ \\
\hline Air dried & $310 \pm 6$ & $266 \pm 6$ & $121 \pm 6$ & $222 \pm 4$ & $152 \pm 2$ & $319 \pm 15$ & $135 \pm 4$ & $122 \pm 11$ \\
\hline Lyophilized & $163 \pm 6$ & $372 \pm 8$ & $178 \pm 8$ & $243 \pm 5$ & $186 \pm 5$ & $172 \pm 10$ & $133 \pm 6$ & $155 \pm 4$ \\
\hline
\end{tabular}

By investigating the plants after the preservation procedures, the highest total polyphenol contents were measured after air-drying in case of basil and lemongrass, while lyophilization seemed to be the most efficient method in case of thyme, rosemary, mint and coriander. After drying the highest value was measured in parsley and chives, because by examining these plants, we have got the highest results after this treatment.

\section{Results of flavonoid content}

Flavonoid contents of the plants related to dry matter can be seen in Figure 2. According to that, raw samples showed the highest concentrations, just like in case of total polyohenol compounds.

The most outstanding result can be seen by observing lemongrass (719 $\pm 36 \quad \mathrm{mgCE} / 100 \quad \mathrm{~g})$, followed by rosemary $(541 \pm 17 \mathrm{mgCE} / 100 \mathrm{~g})$. Flavonoid content of raw basil was $356 \pm 3 \mathrm{mgCE} / 100$ $\mathrm{g}$, while coriander had a flavonoid content of $252 \pm 7 \mathrm{mgCE} / 100 \mathrm{~g}$. Approximately $200 \mathrm{mgCE} / 100 \mathrm{~g}$ was measured in case of thyme and chives too. Lower values could be measured only in mint and parsley.
By investigating air-dried plants, the highest value was shown by lemongrass (675 $\pm 22 \mathrm{mgCE} / 100 \mathrm{~g})$, followed by basil $(317 \pm 13 \mathrm{mgCE} / 100 \mathrm{~g})$ and thyme $(241 \pm 5 \mathrm{mgCE} / 100 \mathrm{~g})$. The results were lower than 200 $\mathrm{mgCE} / 100 \mathrm{~g}$ in case of mint and coriander. Three samples showed results under $100 \mathrm{mgCE} / 100 \mathrm{~g}$, which were rosemary, parsley and chives.

The results of the lyophilized samples showed the following tendencies: Thyme had the highest flavonoid content with a value of $455 \pm 7 \mathrm{mgCE} / 100 \mathrm{~g}$. Lemongrass showed the second highest concentration $(271 \pm 8 \mathrm{mgCE} / 100 \mathrm{~g})$, and mint was the next one with $216 \pm 7 \mathrm{mgCE} / 100 \mathrm{~g}$. The other samples presented results under $200 \mathrm{mgCE} / 100 \mathrm{~g}$.

By the determination of flavonoid contents of the dried samples, a value over $200 \mathrm{mgCE} / 100 \mathrm{~g}$ could be seen only in case of lemongrass. Three plants (basil, thyme, coriander) showed results over $100 \mathrm{mgCE} / 100$ $\mathrm{g}$, while we have measured flavonoid content under $100 \mathrm{mgCE} / 100 \mathrm{~g}$ in case of rosemary, mint, parsley and chives. 
The following data became available by investigating each plant:

In case of basil, the raw sample showed the highest concentration $(356 \pm 3 \mathrm{mgCE} / 100 \mathrm{~g})$. Air-dried basil also had a high flavonoid content with a value of $317 \pm 13 \mathrm{mgCE} / 100 \mathrm{~g}$. Nevertheless, lyophilization (177 $\pm 7 \mathrm{mgCE} / 100 \mathrm{~g})$ and drying $(122 \pm 2 \mathrm{mgCE} / 100 \mathrm{~g})$ decreased significantly the flavonoid concentration of basil.

In case of thyme, it is remarkable that the highest flavonoid content could be measured in the lyophilized sample $(455 \pm 7 \mathrm{mgCE} / 100 \mathrm{~g})$, followed by air-dried (241 $\pm 5 \mathrm{mgCE} / 100 \mathrm{~g})$, raw $(197 \pm 9 \mathrm{mgCE} / 100$ $\mathrm{g})$ and dried $(126 \pm 9 \mathrm{mgCE} / 100 \mathrm{~g})$ samples.

Figure 2: The spices flavonoid content for dry matter

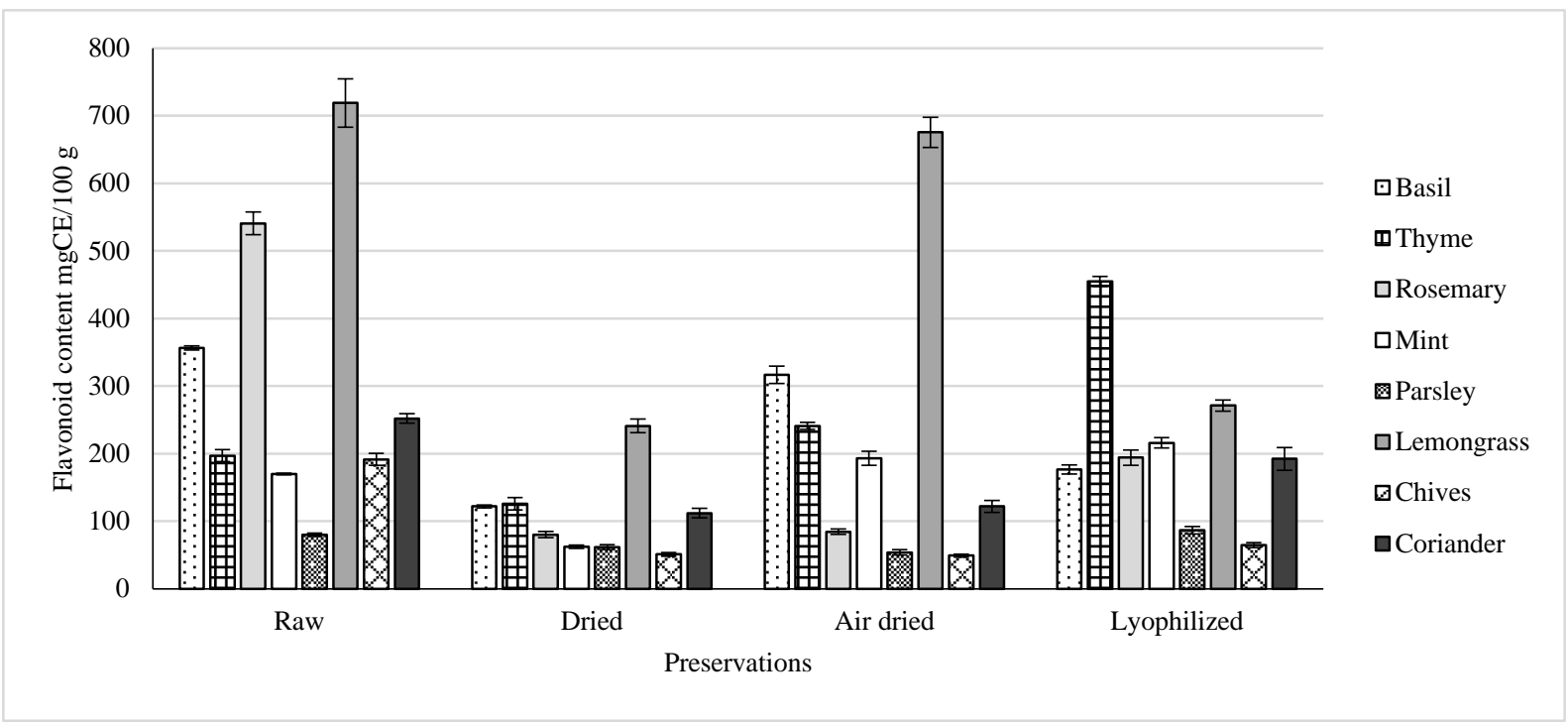

The highest flavonoid content of rosemary was measured in the raw plant $(541 \pm 17 \mathrm{mgCE} / 100 \mathrm{~g})$. The next value was much lower, which was measured in the lyophilized sample $(194 \pm 11 \mathrm{mgCE} / 100 \mathrm{~g})$, followed by the dried and air-dried samples, which showed similar values (dried: $80.3 \pm 4.6 \mathrm{mgCE} / 100 \mathrm{~g}$; air-dried: $84.5 \pm 4.0 \mathrm{mgCE} / 100 \mathrm{~g}$ ).

Mint and thyme showed similar tendency with different values. The highest value could be measured after lyophilization $(216 \pm 7 \mathrm{mgCE} / 100 \mathrm{~g})$, followed by air-dried $(193 \pm 10 \quad \mathrm{mgCE} / 100 \mathrm{~g})$, raw $(170 \pm 1$ $\mathrm{mgCE} / 100 \mathrm{~g})$ and dried $(62.3 \pm 2.6 \mathrm{mgCE} / 100 \mathrm{~g})$ samples.

In case of parsley, we could measure flavonoid contents under $100 \mathrm{mgCE} / 100 \mathrm{~g}$ in each sample. The concentrations were $86.9 \pm 5.6 \mathrm{mgCE} / 100 \mathrm{~g}$ in case of the lyophilized sample, followed by the raw one $(80.0 \pm 2.2 \mathrm{mgCE} / 100 \mathrm{~g})$. The lowest value was shown by the air-dried sample $(53.9 \pm 4.0 \mathrm{mgCE} / 100 \mathrm{~g})$. The result after drying was $61.8 \pm 3.6 \mathrm{mgCE} / 100 \mathrm{~g}$.

Lemongrass showed high values in its original form and after every preservation method too. $719 \pm 36$ $\mathrm{mgCE} / 100$ was measured in the raw plant, followed by the air-dried sample with a value of $675 \pm 22$ $\mathrm{mgCE} / 100$ g. Dried $(241 \pm 10 \mathrm{mgCE} / 100$ g) and lyophilized (271 $\pm 8 \mathrm{mgCE} / 100 \mathrm{~g})$ samples showed similar results.
The flavonoid content of chives has been decreased by the different preservation techniques significantly. The raw sample contained almost 200 $\mathrm{mgCE} / 100 \mathrm{~g}$ of flavonoids, while its flavonoid content has decreased after drying $(51.0 \pm 3.0 \mathrm{mgCE} / 100 \mathrm{~g})$, air-drying (49.3 $\pm 2.1 \mathrm{mgCE} / 100 \mathrm{~g})$ and lyophilization (64.9 $33.8 \mathrm{mgCE} / 100 \mathrm{~g})$.

In case of coriander, the highest flavonoid content could be measured in the raw sample (252 \pm 7 $\mathrm{mgCE} / 100 \mathrm{~g}$ ), followed by the lyophilized one $(192 \pm 17 \mathrm{mgCE} / 100 \mathrm{~g})$. The concentration of flavonoids decreased considerably during drying $(112 \pm 7 \mathrm{mgCE} / 100 \mathrm{~g})$ and air-drying (122 \pm 9 $\mathrm{mgCE} / 100 \mathrm{~g})$.

In case of the flavonoid contents related to the original matter, it can be seen, that raw samples had the lowest concentrations, except in case of rosemary. The highest values were shown by rosemary and lemongrass samples, while the lowest concentration could be measured in parsley.

By investigating the plants after the preservation procedures, the highest flavonoid contents were measured after air-drying in case of basil and lemongrass, while lyophilisation seemed to be the most efficient method in case of thyme, rosemary, mint, parsley, chives and coriander, because by examining these plants, we have got the highest results after this treatment. 
Plants flavonoid content for original matter (mgCE/100 g)

\begin{tabular}{lcccccccc}
\hline & Basil & Thyme & Rosemary & Mint & Parsley & Lemongrass & Chives & Coriander \\
\hline Raw & $36.0 \pm 0.3$ & $41.0 \pm 1.9$ & $83.8 \pm 2.6$ & $28.7 \pm 0.2$ & $10.8 \pm 0.3$ & $84.1 \pm 4.2$ & $15.4 \pm 0.7$ & $17.7 \pm 0.5$ \\
Dried & $122 \pm 2$ & $126 \pm 9$ & $80.3 \pm 4.6$ & $62.3 \pm 2.6$ & $61.8 \pm 3.6$ & $241 \pm 10$ & $51.0 \pm 3.0$ & $112 \pm 7$ \\
Air dried & $295 \pm 12$ & $224 \pm 5$ & $81.3 \pm 3.8$ & $184 \pm 10$ & $52.1 \pm 3.9$ & $672 \pm 22$ & $48.0 \pm 2.1$ & $121 \pm 9$ \\
Lyophilized & $108 \pm 4$ & $438 \pm 7$ & $121 \pm 7$ & $204 \pm 7$ & $81.1 \pm 5.2$ & $259 \pm 8$ & $64.0 \pm 3.7$ & $181 \pm 16$ \\
\hline
\end{tabular}

\section{CONCLUSIONS}

Our investigations included eight spices, which had been preserved by different methods (drying, in oven, drying on room temperature, lyophilisation). Dry matter contents and the concentrations of antioxidant compounds of the raw and preserved samples have been measured.

Overall, it can be declared that raw samples had low dry matter contents. What is more, after lyophilisation, basil and rosemary had lower dry matter contents than the other plants.

During the analysis of antioxidant compounds, we have calculated the results for their dry matter and original matter too. Raw plants, which had high water content showed higher results for dry matter.

The results of total polyphenol content were really various.

Based on the results calculated based on the dry matter, we have realized that polyphenol content of the raw samples was the highest, followed by the lyophilized samples. The third group was samples which have been dried on room temperature, and oven-dried samples showed the lowest polyphenol content.

As for the results calculated for original matter, the lowest results could be observed in case of raw plants. The highest values could be measured in case of the lyophilized samples, followed by the samples dried on room temperature, then the samples dried in the oven. It can be declared, that lyophilisation was the method which could help to preserve polyphenol compounds.
In case of flavonoid content, the highest values could also be observed in case of raw plant samples, followed by the samples dried on room temperature, lyophilized and oven-dried samples.

According to the results calculated for the original matter, it can be seen, that raw samples contained flavonoids in the lowest concentrations, except in case of rosemary. The highest values could be observed in case of air-dried and lyophilized samples, which were followed by the oven-dried samples. For the preservation of flavonoids, lyophilisation and airdrying were the most sufficient methods, in case of original matter.

Based on our results, out of the different preservation methods, lyophilisation would be the most suitable to preserve spices. Nevertheless, airdrying should not be ruled out, because we have measured high values in case of this method too. We also have to point out that we got various results, which could be influenced by the differences in the water content, total polyphenol and flavonoid content of the plants, because their temperature sensitivity and concentrations could be diverse too. We are going to investigate these hypothesises in the future.

\section{ACKNOWLEDGEMENTS}

The publication is supported by the EFOP-3.6.116-2016-00022 project. The project is co-financed by the European Union and the European Social Fund.

\section{REFERENCES}

Bernáth, J. (2000): Gyógy- és aromanövények. Mezőgazda Kiadó. ISBN 9639239968 pp. 13-14.

Bernáth, J.-Németh, É. (2007): Gyógy- és füszernövények gyüjtése, termesztése és felhasználása. Mezőgazda Kiadó. ISBN 978963-286-493-8. p. 256.

Czipa, N. (2014): Élelmiszeranalitika gyakorlati jegyzet. Debreceni Egyetem. Élelmiszertudományi Intézet. p. 68.

Embuscado, E. M. (2015): Herbs and spices as antioxidants for food preservation. In: Handbook of Antioxidants for Food Preservation (Ed.: Fereidoon Shahidi) Woodhead Publishing is an imprint of Elsevier. ISBN 987-1-7842-089-7 pp. 251-282.

Gibson, M. (2018): Food Science and the Culinary Arts. Academic Press is an impront of Elsevier. ISBN: 978-0-12-81 1816-0. p 507.
Kim, D. O.-Jeong, S. W.-Lee, C. Y. (2003): Antioxidant capacity of phenolic phytochemicals from various cultivas of plums. Food Chemistry, 81, 321-326

Murica, M. A.-Egea, I.-Romojaro, F. - Parras, P. - Jimenez, A. M. Martinez-Tome (2004): Common food additives-influence of irradtiation procedure. Journal of Agricultural and Food Chemistry, 52, 1872-1881.

Shahidi, F. (2015): Antioxidants: principles and applications. In: Handbook of Antioxidants for Food Preservation (Ed.: Fereidoon Shahidi) Woodhead Publishing is an imprint of Elsevier. ISBN 987-1-7842-089-7 pp. 1-16.

Singleton, V. L.-Orthofer, R.-Lamuela-Raventos, M. (1999). Analysis of total phenols and other oxidation substrates and antioxidants by means of FolinCiocalteu reagent. Methods in Enzymology, 299, 152-178. 
